\title{
Um Pranto Utópico: Travessias De Um Infantil Alienante
}

\author{
Marcos Pippi de Medeiros1 \\ Edson Luiz André de Sousa2
}

\section{ResUmo}

Através deste ensaio, procuramos discutir a noção de "infantil", abordando tanto sua constituição, como sua alienação fundante enquanto consciência ou interioridade. A leitura do livro "História do Pranto", de Alan Pauls, serviu como dispositivo a partir do qual procuramos analisar os mecanismos anestésicos da experiência no contemporâneo, em que essa dimensão do infantil está "forcluída", como também, suas possíveis consequências para nossa inclinação ao sonho utópico, o deixando a mercê de aderências ou colagens com esses ideais anestésicos, mas também, apostando no infantil que desde as formulações freudianas, se apresenta como fator de resistência, através da potência poética que constitui sua utopia.

PALAVRAS-ChaVe: Infantil, alienação, contemporâneo, utopia, psicanálise.

\footnotetext{
1 Professor do curso de Psicologia da Universidade Franciscana - UFN; Doutor em Psicologia Social e Institucional pela Universidade Federal do Rio Grande do Sul - UFRGS; integrante do LAPPAP Laboratório de Pesquisa em Psicanálise, Arte e Política. Rua Ernesto Lopes, 20 97110-280 Santa Maria, RS, Brasil e-mail: marcospippi.m@gmail.com

2 Orientador; Professor do Programa de Pós-Graduação em Psicanálise: clínica e cultura da Universidade Federal do Rio Grande do Sul - UFRGS; professor titular do Departamento de Psicanálise e Psicopatologia do Instituto de Psicologia - UFRGS; doutor em Psicanálise e Psicopatologia pela Universidade de Paris VII. Rua Fernandes Vieira, 474/32 90035-090 Porto Alegre, RS, Brasil e-mail: edsonlasousa@uol.com.br
} 
Antes do humano, um inumano brande em nós, seu pranto e seu desamparo de infans. Melodias de um desamparo arcaico para com as próprias palavras. O assombro de uma dupla dimensão do inumano nos assalta. Isto implica que estejamos na vida confrontados, de um lado, ao inumano que o caminho do "desenvolvimento" nos conduz, consolidando em seu curso um constrangimento ao 'humano' a se fazer inumando. No entanto, concomitantemente, nos cabe saber distinguir este inumano, o do "desenvolvimento", a este outro "de que a alma é refém", cerne de nossa angústia: "o estado de espírito assombrado por um hóspede familiar e desconhecido que o agita, fá-lo delirar, mas também pensar. Se pretendemos excluí-lo, se não lhe damos uma saída, agravamo-lo." (LYOTARD, 1997. p. 10).

À velocidade imposta pelo desenvolvimento (a velocidade deste discurso "sobre rodas", como disse Lacan acerca do discurso do capitalista) uma lentidão inverte seu curso rumo a um "tempo perdido". Esta é a experiência de um inumano, proposta por Jean-François Lyotard (1997): que ele descenda de uma miséria inicial da infância, ou então, como a capacidade mesma de se adquirir uma "segunda natureza" que lhe dá (ao humano) uma aptidão à vida comum, mas que, de qualquer forma, está assentada sobre a primeira, sobre o "rastro de uma indeterminação, de uma infância, que persiste mesmo na idade adulta. (...) Desprovida da palavra, incapaz da paragem certa, hesitante quanto aos objetos de seu interesse, inapta no cálculo de seus benefícios, insensível à razão comum, a criança é eminentemente humana, pois sua aflição anuncia e promete os possíveis." (LYOTARD, 1997. p. 11). O humano que caminha entre sua indeterminação "nativa" e a razão que foi instituída ou que virá a instituir-se, enfim, e que se usa desde Freud nomear como "castração".

É a partir disso que Lyotard formula uma questão por demais pertinente: "o que resta de <<político>> que não seja a resistência a este inumano? E que mais resta, para opor resistência, que a dívida que toda alma contraiu com a indeterminação miserável de sua origem, na qual não cessa de nascer?" (LYOTARD, 1997. p. 15). Assim, bastaria não esquecê-la, a infância, para resistir; tarefa que é própria do pensamento e da qual a arte e a literatura prestam testemunho. A palavra, suas imagens, precisa brotar desse inumano precário como defesa frágil a outro inumano, ainda mais feroz, para o qual tendemos; o inumano do desenvolvimento e suas formas absolutas.

Isso também faz lembrar Russell Jacoby (2007) ao dizer, recorrendo ao argumento de Hokheimer, de que os sonhos utópicos da infância são, desde a tenra 
idade, cortados pela maquiagem moderna, e também, que esta colonização do espaço infantil possa por em xeque uma imaginação independente, tornando-nos com menos recursos e inclinações para o sonho utópico.

O infantil diz desse estado de prematuração. Permanece, justamente por isso, como um fator fundamental em nosso impulso utópico: dizer, o que ainda não é. $O$ que talvez nunca venha a ser e que não poderia ter nenhuma realidade senão pelas palavras com as quais nos antecipamos. Isso, uma vez que ele nos inclina a um tipo de construção ficcional, na medida em que não poderia ser "acessada" de outra forma, e poética, uma vez que se constitui nesse desamparo (para com as palavras), modifica o Campo do Outro, altera sua tessitura simbólica.

Assim também, propusemos que esse "fator infantil" é condição da utopia. Essa capacidade de se criar ilhas de papel. De, com as palavras, fazer furos, produzir contra fluxo, resistir às imensas desertificações da vida cotidiana. Para a psicanálise, no contemporâneo, trata-se de renovar seu compromisso ético com o sujeito do desejo em seu caráter polimorfo e infantil. Para o sujeito com sua verdade singular, trata-se de resistir, fazendo objeção a todo saber de mestria. Também na cultura, quando o infantil fica forcluído dos discursos, nossa capacidade utópica se rarefaz; é quando ficamos mais a mercê dos Ideais totalitários da cultura.

Minhas associações me conduziram a um livro. Livro que li pela primeira vez, qual um encontro com o unheimlich. Um livro que "me olhou", me encontrou desde a estante da livraria com sua "capa", cuja imagem era a de uma criança a observar pelo vidro da janela, vestida de super-homem. Essa obra foi um encontro com uma espécie de duplo, que ao ser encontrado com sua narrativa ácida, traz uma ideia também de como nos identificamos com o texto literário e sua posição entre o singular e algo de um universal ou social.

A história do pranto, de Alan Pauls (2008), narra a trajetória deste menino, sem nome, que aos quatro anos de idade, diferentemente das outras crianças desesperadas para falar, poderia ficar horas apenas escutando:

O que o salvou não foi a compleição de aço do super-herói que ele evoca, como poderia parecer à primeira vista e como logo irão cuidar de repetir os relatos destinados a manter viva essa façanha, a mais chamativa, senão a única, de uma infância que, aliás, destinada desde o início a não chamar a atenção, prefere ir levando em atividades solitárias, leitura, desenho, a juveníssima televisão da época, indícios de que isso que em geral chamamos de mundo interior e que define, ao que parece, crianças um tanto esquisitas, 
nele é consideravelmente mais desenvolvido do que na maioria dos meninos de sua idade (PAULS, 2008. p. 06).

Salvo por sua sensibilidade, assim acredita, secretamente, faz do seu superhomem algo marcado pela fragilidade; "é uma fragilidade orgânica, original, a única, aliás, que o obriga, aos quatro anos, a pensar no impensável por excelência, na possibilidade de que o homem de aço morra." (PAULS, 2008. p. 07). Um "superhomem" que sofre de um interesse por tudo que é dor:

A dor é sua educação e sua fé. A dor o torna crente. Acredita apenas, ou sobretudo, naquilo que sofre. Acredita em Super-Homem, em quem, por outro lado, é evidente que não acredita, não importa a prova contrária que apresente seu pobre corpo de quatro anos enfronhado numa roupa de superherói atravessando o vidro da janela francesa da sala da Ortega y Gasset (PAULS, 2008. p. 11).

Seu pranto e sensibilidade tornam-se lugar de reconhecimento familiar, sobretudo do pai, que parecer gozar de seu padecimento. Chora apenas para o pai:

\begin{abstract}
Afinal, ao chorar compra imediatamente a admiração de seu pai. Pode sentir a que ponto sua condição de lágrima fácil o transforma, de algum modo, num troféu, em algo que seu pai pode passear pelo mundo com um orgulho único, que não terá de compartilhar com nenhum outro pai, ao contrário das habilidades esportivas, da lascívia precoce, e mesmo da inteligência, virtudes infantis proveitosas, porém por demais comuns (PAULS, 2008. p. 23).
\end{abstract}

Ao mesmo tempo, indaga a precariedade infantil de sua condição, na medida em que se pergunta, "de onde se arrancam as coisas, de onde que não seja desse interior impreciso, brando, sempre saturado de emoção, mas tão convincente e extorsivo, por outro lado, quanto sua contrapartida exterior, o fora igualmente imundo para o qual as coisas devem sempre ser arrancadas?" (PAULS, 2008. p. 25).

Funcionário exemplar, soldado fiel do Outro, faz de sua sensibilidade um instrumento. Chega até mesmo a indagar como poderia, de fato, fazer de sua rara posição, profissão: "por que não vira padre? Por que não psicanalista, motorista, michê, recepcionista de um desses serviços de assistência ao suicida que nos filmes dissuadem de se atirar no vazio com um punhado de frases oportunas que falam pelo telefone enquanto se equilibram numa cornija?" (PAULS, 2008. p. 43). No entanto, ele não pensa em lucrar com um talento que, no mais das vezes, só lhe causa náusea e o entedia desde a sua descoberta.

A primeira questão a se apresentar, diz respeito ao paradoxo que a posição do sujeito vai encontrar frente a sua submissão ao poder, problemática esta presente desde Hegel, passando por Nietzsche e as formulações psicanalíticas. É dizer que o 
poder ao qual o sujeito se submete é, ao mesmo tempo, lugar de sua constituição, de sua alienação fundante como consciência ou interioridade: "a sujeição é o processo de devir subordinado ao poder, assim como o processo de devir sujeito." Seja como 'consciência desventurada' (Hegel), como 'má consciência' (Nietzsche), ou o sujeito culpado freudiano, o paradoxo se apresenta ao atrelar uma origem de assujeitamento, de violência simbólica à constituição mesma do sujeito. Uma espécie de apaixonamento por esta instância mesma que nos submete e disciplina.

O poder subordina e cria o sujeito neste ato de subordinação como identidade ao assumir uma forma, uma topologia psíquica. Como postula Judith Butler (1997), a consciência que reflete sobre si mesma desdobra a instância do poder, interiorizandoa. Fonte de um desejo por demais explorável, na medida em que é sustentado no amor, no laço libidinal que atrela o senhor e o escravo em mútua interdependência. Ao seu desamparo de origem, o infans antecipa sua imagem, alienando-se a essa instancia como promessa de sobrevivência e amparo, o que faz deste lugar da autoridade alienante um lugar de dívida passional, cuja dupla negação pelo sujeito, funda seu eu como lugar de desconhecimento e alienação, mas também de individuação.

As identidades passam a serem questionadas não como lugar de verdade ou ficção singular do sujeito, mas como expressão das formas previamente atreladas a esse "poder constituinte" que delimita as condições de ser, as formas de existência. Uma questão se faz assim central: como podemos falar em resistência, em formas de emancipação do sujeito na medida em que abolir a instância deste poder constituinte é, ao mesmo tempo, abolir a alteridade necessária para a existência do próprio sujeito? Como podemos pensar esse elemento, ao mesmo tempo subversivo no sujeito na medida em que constitui uma ficção singular, uma disfunção constitutiva em ser simplesmente uma expressão pura do poder que o constitui, mas que a ele resiste, sintomaticamente, como sujeito? E isto considerando que não irá se constituir como expressão passiva, literal, da norma que o inscreve como assujeitado as formas do poder, a instância simbólica e as suas formas e condições sociais de exploração e alienação. Algo do desejo não pode ser simplesmente sobreposto à demanda que o forja. Que o sujeito faça sintoma a partir da psicanálise, como forma de resistência à completa alienação a esta instância demandante, não resolve o problema de ele estar, ainda, atrelado a uma dicotomia. Por negação, pode produzir algo ainda mais 
alienante ao confirmar apenas o poder normatizador, na mesma medida em que 0 nega, ou se contrapõe, especularmente, a ele.

Freud (1930 [1929]), em "O mal-estar na Cultura", nos apresenta a ideia de um desamparo constitutivo como uma condição a que cada um está submetido na vida, desde a origem, e cujos efeitos tentamos reduzir pelas construções culturais, pelo laço com o outro, para tentar aliviar, com alguns amparos, essa solidão existencial. Solidão que diz de nosso passado de infans, precário com as palavras, sob a ameaça que implica um corpo também insuficiente, onde o Outro vai marcar com seu desejo, a presença de Eros e, também, a cifra de um enigma cuja inscrição, nos oferece uma imagem onde nos desconhecemos. E, com alguma sorte, a palavra como um dom, para tentar inventar os caminhos em nosso destino mortal.

Para Lacan, leitor leal de Freud, isto é o resultado de uma condição de "fetalização", no "filhote do humano", cuja implicação nos põe diante de uma prematuração desde a origem, que faz com que estejamos sempre em descompasso entre nossas possibilidades orgânicas e subjetivas, e as demandas sociais que nos concernem. 3 Ou seja, precisamos sempre responder e produzir sentido em relação a questões para as quais não estamos ainda, com capacidade de verdadeiramente poder responder.

Compreendo que a construção lacaniana de quatro discursos iniciais, transitando de um a outro em um quarto de volta e dispondo em diferentes lugares os elementos que originalmente constituem a fórmula da própria constituição fantasmática do sujeito (cindido entre saber e verdade) nos aponta, realmente, um terreno fecundo para levar adiante algumas destas questões. Conceber o discurso como discurso produtor de discursos, tal como nos mostra a articulação do Discurso do Mestre, repetindo em sua disposição, a própria formulação do fantasma, nos traz, de saída, para o "campo do Outro", da alteridade radical que nos permite indagar pela possibilidade de saber (gozar), como também, de constituir para si um território de verdade (como ficção erigida no limite do saber, como Gozo do Outro). Isto, uma vez que:

é no instante mesmo em que o S1 intervém no campo já constituído dos outros significantes, na medida em que eles já se articulam entre si como tais, que ao intervir junto a um outro, do sistema, surge isto, $\$$, que é o que chamamos de sujeito como dividido. (...) Eis porque é de uma articulação lógica que se trata na fórmula pela qual o saber é o gozo do Outro. Do Outro,

3 Ver O estádio do Espelho como formador da função do [eu]. In. LACAN, J. Escritos. Rio de Janeiro; Jorge Zahar Editor, 1998.

Psicanálise \& Barroco em revista | v.17, n. 3 | dezembro de 2019 
obviamente, na medida em que faz surgir como campo - posto que não há nenhum Outro - a intervenção do significante. (LACAN, 1992. p. 13).

De qualquer forma, esta formulação ficaria inacabada se não considerarmos que desta operação lógica cai um resto, marca de uma perda de acesso a qualquer saber como absoluto. Objeto causa de desejo, resto de uma divisão que limita a possibilidade do saber (Gozo do Outro), constituindo o sujeito do inconsciente.

Isto quer dizer que a perda do objeto é também a hiância, o buraco aberto em alguma coisa, que não se sabe se é a representação da falta em gozar, que situa a partir do processo do saber na medida em que ganha ali um acento totalmente diverso, por ser desde então saber escandido pelo significante (LACAN, 1992. p.18).

Disto pode deduzir-se, a partir da função de seus elementos, a indagação pela verdade que o sujeito formula a qualquer saber de Mestria. Para tanto retomo, ainda que de maneira pontual, algumas formulações acerca do Discurso do Mestre, do Senhor, e sua relação com o saber do escravo:

S1 S2

$\$ @$

Tendo na posição de agente do discurso, S1, o discurso do Mestre "antigo" espera obter do escravo, na posição de outro, um saber, como meio de gozo para o senhor. Trata-se de um discurso que visa em sua produção, objetos mais-de-gozar para o mestre (por onde talvez se esclareça a concepção lacaniana do saber, como gozo do Outro). "É isto, em suma, não mais que isto, que o senhor tinha que fazer o escravo pagar, como único possuidor dos meios de gozo" (LACAN, 1992. p.83). O discurso do Mestre, erigido como lugar da Lei, sustenta uma posição de verdade para o sujeito. Verdade esta que o escravo vem a subverter com seu desejo como desejo do Outro.

Estas são algumas questões iniciais que o texto de Butler suscita, atualizando uma problemática já presente, nessas leituras de Lacan pelo "Avesso da psicanálise". Sua aproximação com a problemática do sujeito e as instancias do poder normativo são realmente pertinentes. Ela questiona os rumos dos movimentos sociais de resistência às lógicas do poder e, também, vai ao cerne dos fracassos em se produzir 
outra ordem de repetição destas estruturas que possa se apresentar verdadeiramente como invenção ou criação.

De fato, para o personagem de "História do pranto", fazer-se assim, instrumento alienado do Outro, não se mostra mais uma opção. Seu basta, surge pela potência de uma recusa em conversar, em "se abrir" com seu pai e chorar para ele. Mas, para ele, isso acaba por produzir uma posição igualmente incômoda, uma espécie de anestesia que o torna incapaz de compartilhar da dor, solidarizar-se com o pranto alheio. Isto se evidencia quando, diante da televisão a mostrar o corpo de Allende, signo da morte de uma utopia de esquerda na América Latina, mesmo diante do choro convulsivo de seu amigo, não Ihe foi possível nenhum pranto. A dor de não poder se ligar ao amigo, verdadeiramente, a nenhuma dor a sua volta porque havia prometido, a si mesmo, nunca mais chorar.

Mas,

talvez chorar seja muito geral; talvez não se deva dar a todos os choros a mesma significação; talvez haja no mesmo enamorado vários sujeitos que se empregam em modos vizinhos, mas diferentes de "chorar". Qual é esse "eu" que tem "lágrimas nos olhos"? Qual é esse outro que um dia desses estava "à beira das lágrimas"? Quem sou eu que choro "todas as lágrimas do meu corpo"? Ou derramo ao acordar "uma torrente de lágrimas"? Se tenho tantas maneiras de chorar, é porque, talvez, quando choro, me dirijo sempre a alguém, e o destinatário das minhas lágrimas não é sempre o mesmo (...) (BARTHES, 1994. p. 42).

Não é por acaso que essa citação de Barthes me vem à memória nesse momento. Deste fragmento dos "Fragmentos de um discurso amoroso", algo nos lembra da mobilidade metonímica dos significantes e de sua capacidade metafórica, que nos resguarda de um destinatário que permaneça sempre unívoco.

Assim também, diante dessa "televisão", duas outras evocações; a primeira, a crítica nietzschiana, que nos leva a pensar como, modernamente, a renúncia à dor como experiência (pelas promessas da ciência) acaba por nos provocar uma espécie de anestesia, através da qual Nietzsche tenta erigir sua Gaia ciência, cuja experiência do sofrimento não é apenas, não evitada, mas desejada, para que então, "se revelasse igualmente o seu poder contrário, sua tremenda capacidade para fazer brilhar novas galáxias de alegria" (NIETZSCHE, 2001. p. 12). Neste sentido, a crítica da verdade como absoluta, deste ideal que a atravessa, põe, também, a ciência, a serviço desta conservação, deste amortecimento de toda potência criadora e multiplicadora de sentidos. Mas, talvez existam outras paisagens possíveis neste 
impulso à formação de metáforas que podemos encontrar no mito e, de forma geral, também na arte:

Constantemente ele embaralha as rubricas e compartimentos dos conceitos propondo novas transposições, metáforas, metonímias, constantemente ele mostra o desejo de dar ao mundo de que dispõe o homem acordado uma forma tão cromaticamente irregular, inconsequentemente incoerente, estimulante e eternamente nova como a do mundo do sonho. (NIETZSCHE, 1999. p.59).

A segunda formulação possível, ante a cena de nosso personagem, atônito, com o amigo, frente à televisão, remete aquilo que Lacan, em "A terceira", vem a produzir acerca dessas "engenhocas", que mediam uma relação possível, porém anestesiada com o mundo. Do mesmo modo, a possibilidade de que venhamos, nós mesmos, a convertermo-nos nessas maquininhas, exaltadas nos discursos científicos com suas promessas tecnológicas:

Fizemos desde então alguns pequenos progressos, mas no que é que isso dá, afinal de contas, a ciência? Isso nos dá alguma coisa para colocar no lugar do que nos falta na relação, na relação do conhecimento, como dizia há pouco, nos dá nesse lugar, afinal de contas o que, para a maioria das pessoas, todos aqueles que aqui estão em particular, se reduz a engenhocas: a televisão, a viagem à Lua e, ainda assim, a viagem à Lua vocês não farão, só existem alguns selecionados. Mas vocês vêem isso na televisão. É isso, a ciência parte daí. (...) Então aí o círculo se fecha sobre o que acabo de lhes dizer há pouco: o futuro da psicanálise é algo que depende do que advirá desse real, ou seja, se as engenhocas, por exemplo, ganharão verdadeiramente a dianteira, se chegaremos a ser, nós mesmos, verdadeiramente animados pelas engenhocas. Devo dizer que isso me parece pouco provável. Não chegaremos a fazer com que a engenhoca não seja um sintoma, pois ela o é, por enquanto, muito evidentemente (LACAN, Sessão de 31 de outubro de 1974).

No entanto, guardamos uma esperança sempre renovada, de que não nos converteremos nessas maquininhas, como dizia Lacan. Não é fácil, de fato, sustentar essa esperança utópica, por vezes nos falta tempo, em outras o desejo claudica; apesar de tudo, conseguimos, muitas vezes, conferir a vida uma perspectiva trágica, transformando-a - com um ato criativo, ao qual chamamos de utopia -, em uma aventura. Que façamos disso sintoma! Isso resiste! Resistência a essa aderência plena que a ciência, como representante do discurso do mestre moderno, comporta de alienação e anestesia. Como afirma Lacan, "o que se opera entre o discurso do senhor antigo e do senhor moderno, que se chama capitalista, é uma modificação no lugar do saber" (LACAN, 1992. p. 32). Também o lugar da verdade vai ser encontrado, neste sentido, em outro lugar, sustentado pelos novos escravos, eles mesmos, como 
produtos. "Sociedade de consumo, dizem por aí. Material humano, como se anunciou um tempo - sob os aplausos de alguns que ali viram ternura" (LACAN, 1992. p. 33).

Donaldo Schüler (2017) vai situar essa problemática, ao tentar oferecer um contorno para o que vai chamar de "homem unidimensional", como resultado de uma sociedade cuja máquina totalitária, de escravos que produzem escravos, vai ao encontro dessa lógica de consumo, deste material humano do qual nos fala Lacan.

A racionalidade tecnológica, justificada pelo êxito, degrada cuidados sociais. A burocracia, nivelando pluralidades, administra a desumanidade e a injustiça. Como a máquina é mais produtiva do que o indivíduo, o Estado mecanizado age tiranicamente. A sociedade mecanizada requer submissão a poderes anônimos que dessacralizam a vida. A livre eleição de senhores não elimina escravos. A competição consolida quem se instala no poder. (SCHÜLER, 2017. p. 196).

O homem unidimensional vive sem protestar, como bom consumidor de uma realidade totalmente planejada ou fabricada, como também segura: a felicidade é uma mercadoria e, felizes, são os que tem poder aquisitivo para consumi-la. Isto, em um mundo onde a Máquina cria necessidades, encobre as formas de escravidão, afastando, por exemplo, a libido para o inconsciente e desenvolvendo estereotipias, enaltecem o estabelecido, por essa cultura de massas.

De sua parte, Contardo Calligaris (1996) vai chamar de "Narcísico mundo novo" a cultura do narcisismo, na qual as referências puramente imaginárias ocupam lugar entre as decaídas referências simbólicas. Na busca vertiginosa por algum fundamento fixo, o sujeito acaba por ligar-se em uma relação direta com o Real:

(...) a sobrevivência será cultuada como valor supremo, a forma física e a boa fisiologia do corpo como bem objetivo. (...) O discurso científico, por parecer isento do engano das aparências, será considerado como possível fonte de sabedoria. As pessoas se reunirão por critérios reais, pois estes parecerão como únicos autênticos: por exemplo, a cor da pele, o sexo, a preferência sexual entendida como destino fisiológico (CALLIGARIS, 1996. p. 51).

Disto sobrevém a proliferação de discursos nostálgicos e o apego a identidades imaginárias que, uma vez assumidas, tornam-se compactas e imutáveis. Porém, Lacan, em seu capítulo sobre $O$ campo lacaniano, nos adverte de que, quando a sociedade de consumidores reduz o campo do humano a uma produção industrial, este passa a ser um equivalente de um mais-de-gozar qualquer; "além do mais, isso pode pegar. Pode-se bancar o mais-de-gozar, isso ainda atrai muita gente". (LACAN, 1992. p. 84-85). Não estaria aí o grande desafio ético para uma psicanálise nos dias de hoje? 
A forclusão do infantil nos discursos do Mestre contemporâneo, a colonização do espaço da infância, os imensos desertos onde não mais se brinca: tudo isso oferece um pano de fundo melancólico a esse escrito. Isso nos faz pensar que o advento do infantil, por si mesmo, unido às construções da infância e da criança, tão recentes em nossa cultura, institui na aurora de nosso tempo, uma utopia.

O quê dessa verdade melancólica de nosso personagem, anestesiado frente à televisão, a buscar um laço que já não pode sentir. Como um pranto perdido e desejado pode dizer desse infantil esvaziado? O discurso do capitalista para Lacan mantém fora (do discurso), justamente, as coisas do amor, que implicam à impossibilidade da relação sexual postulada pela psicanálise.

O sexual inscreve seu traço mais singular, como sujeito, justamente onde um saber fracassa, ou alguma coisa faz furo no saber do mestre. Não existe relação sexual, postula Lacan no Seminário XX, simplesmente porque não existe, para ele, um significante correspondente ou complementar do lado masculino ou feminino que estabeleça relação, no sentido de um gozo absoluto, uma complementaridade sem falta. O gozo sexual é fálico e, como tal, só se dirige a objetos parciais. O Gozo do Outro é da ordem do real; impossível gozar absoluto cujo acesso instauraria a relação sexual:

\begin{abstract}
quando postulamos que o erotismo coloca a dimensão do Ser em questão, é justamente como transgressão que comporta um dizer, um desser onde 0 sujeito desde um lugar sexuado só poderá situar-se em ex-sistência, ao lugar do ser. (...) Mas, o ser, é o gozo do corpo como tal, quer dizer, como assexuado, pois o que chamamos de gozo sexual é marcado, dominado, pela impossibilidade de estabelecer, como tal, em parte alguma do enunciável, esse único UM que nos interessa, o um da relação sexual (LACAN, 1985. p. 15).
\end{abstract}

Uma consequência desse axioma é estarmos na vida a sós, com nossos fantasmas. Nossa capacidade de laço é sempre precária, porque sustentada no desamparo e nas ficções "não-todas" que somos capazes de produzir. Nosso herói, fracassado, com sua patética fantasia puída de super-homem.

Seu desamparo e fragilidade contrastava com esses "alienígenas" que eram, por exemplo, os militares em sua fantasia infantil: "para ele, sem ir longe, bastam os uniformes. Nunca uma ruga, qualquer nódoa, nenhuma lapela dobrada. Como é possível?" (PAULS, 2008. p. 51.).

Entre os meandros do texto me perco, fracassando em dar conta do livro, mas não sem antes pontuar seu final, demasiado inquietante, com o personagem já mais velho, ante a constatação que o assola. "É simples: não soube o que tinha de saber. 
Não é contemporâneo, nunca o será. Faça o que fizer, pense o que pensar, é uma condenação que o acompanhará para sempre" (PAULS, 2008. p. 84-85).

De fato, nos diz Agamben (2009),

\begin{abstract}
a contemporaneidade, portanto, é uma relação singular com o próprio tempo, que adere a este e, os mesmo tempo, dele toma distâncias; mais precisamente, essa é a relação com o tempo que a este adere, através de uma dissociação e um anacronismo. Aqueles que coincidem muito plenamente com a época, que em todos os aspectos a esta aderem perfeitamente, não são contemporâneos porque, exatamente por isso, não conseguem vê-la, não podem manter fixo o olhar sobre ela. (AGAMBEN, 2009, p. 59).
\end{abstract}

Ser contemporâneo não está dado. Implica a não determinação tão somente de um período de tempo cronológico, tal qual o próprio infantil, mas uma experiência com o tempo, cujo contemporâneo exige algumas condições para quem quiser sê-lo. Não se tem o direito de se dizer contemporâneo sem pagar o preço de sua contemporaneidade: "a contemporaneidade se escreve no presente assinalando o antes de tudo como arcaico, e somente quem percebe no mais moderno e recente os índices e assinaturas do arcaico pode dele ser contemporâneo. Arcaico significa: próximo da Árke, isto é, dá origem" (AGAMBEN, 2009, p. 69).

A primeira condição, é que ser contemporâneo implica não "aderir" ao presente. Ao tentar se encontrar demasiado situado, confortavelmente aderido, sem a devida distância de seu próprio tempo. Se não se produzir inquietação, descentramento, desamparo, se está fora da experiência de ser contemporâneo. É ter com o presente um descompasso que nos faz, inevitavelmente, perdidos de nosso tempo.

A segunda condição para ser contemporâneo é poder suportar a escuridão que emerge de seu tempo. "Contemporâneo é aquele que recebe em pleno rosto o facho de trevas que provém de seu tempo." (AGAMBEN, 2009. p. 64.). Ser contemporâneo é, ainda, para Agamben, uma questão de coragem.

Coragem para olhar para essa escuridão e poder ver a luz que dela emerge e que de nós se distancia. "Ser pontual a um compromisso que só se pode apenas faltar." (AGAMBEN, 2009, p. 65.). O presente é um não vivido no vivido: "é como se aquela invisível luz, que é o escuro do presente, projetasse sua sombra sobre o passado, e este, tocado por esse facho de sombra, adquirisse a capacidade de responder as trevas do agora." (AGAMBEN, 2009. p. 72.). Este movimento de retorno, de escrever o presente a partir da origem, acaba por introduzir descontinuidade no presente, para melhor lê-lo. O desejo, nos lembra Freud, "utiliza uma oportunidade no presente, para projetar, segundo um modelo do passado, uma imagem do futuro" Psicanálise \& Barroco em revista | v.17, n. 3 | dezembro de 2019 
(FREUD, [1908 (2015)]. p. 59.). A utopia freudiana nos deixa esse legado da infância, a nos lembrar de nossa capacidade poética de resistir ao presente, e, a partir de um remetimento a origem, ao criar um futuro utópico que nos indaga. O infantil psicanalítico é uma utopia, também, no que marca como descontinuidade, com um hiato, mas também, como resistência e criação. Existe algo, no contemporâneo, ao qual se precisa resistir. A psicanálise é pelo menos uma das expressões, sintomáticas, dessa urgência subjetiva.

Também, nos aproxima de uma perspectiva a formular: a de que esse olhar constitui uma imagem utópica, quais "âncoras simbólicas" que nos permitem criar, na escuridão, a partir de uma experiência expropriada do presente. $O$ aproximar-se desse infantil, singular e insabido, rastro de um grito inumano em nós que ressoa tal qual um pranto antigo e insistente, como condição de uma utopia que nos retire da aderência do presente. Mas como?! "A vida é inexata, cada vez que insistimos e respondemos a ela com exatidão sacrificamos algo de essencial, (...) que o corpo tem feridas e cicatrizes, que a vida está cheia de curativos, que os sonhos envelhecem e que inevitavelmente os objetos estragam" (SOUSA, 2007. p. 11-12). Trata-se de afirmar uma utopia que contra a anestesia da realidade, necessita de quem ainda se importe com a dor dos outros, reposicionando o sonho utópico para mais ao alcance das mãos.

O infantil, figura aqui como um resto, resto de afeto ou traço desse pranto alienado, mas também como um rasgo ou hiato, entre o traço que marca uma origem e uma realidade possível de se partilhar com o outro. Freud colocou essa questão como o cerne do conceito mais fundamental da clínica psicanalítica que é a transferência, ou Amor de transferência. Esse desejo de alienação que o analista "suporta", na clínica, é via também de uma experiência de fala singularizante. Uma possibilidade de subverter uma ordem de sentido, ou seja, uma experiência que permita o jogo com esses significantes vindos do Outro. Desgastá-los, puí-los e, assim, construir uma via singular para além desse mandato alienante.

Talvez não precisemos de um Super-Homem em um uniforme impecável e reluzente, cruzando os céus qual um foguete. Talvez nossa utopia possa ser qual uma fantasia gasta e puída, furada e remendada, mas que, no entanto, parafraseando Ernst Bloch, nos ajude a atravessar o obscuro do instante. Que o infantil possa ser uma imagem que nos ajude a transpor a porta de vidro invisível a nos separar do mundo e do outro, tendo apenas nossa sensibilidade como escudo e potência. 
O infantil, pelo rastro dessa indeterminação, dessa precariedade, sustenta nossas utopias. Assim também vivemos de tecer essa teoria frágil, em torno ao vazio, pelas bordas de um indizível que recuperamos, apenas pelas utopias/palavras que construímos, ou somos capazes de construir. A verdade, como a utopia é sempre não-toda. Sua "vocação para o fracasso", como toda teoria sexual infantil, implica um resguardar de seu próprio lugar (da utopia), como também, assinalar o quanto, dessa verdade do sujeito, só se pode dizer parcialmente, uma vez que sempre nos faltarão as palavras. 


\section{REFERÊNCIAS:}

AGAMBEN, G. O que é o contemporâneo? E outros ensaios. Chapecó: Argos, 2009.

BARTHES, R. Fragmentos de um discurso amoroso. Rio de Janeiro: Francisco Alves, 1994.

BUTLER, J. Mecanismos psíquicos del poder: teorías sobre la sujeción. Valência: Ediciones

Cátedra, 1997.

CALLIGARIS, C. Narcísico mundo novo. Crônicas do individualismo cotidiano. São Paulo:

Editora Ática, 1996.

DADOUN, R. UTOPIA: a emocionante racionalidade do inconsciente. Tradução: Elemar do Amor Divino [uso interno à disciplina "A Melodia das Coisas”, PPGPSI-UFRGS, 2015/2]. http://www.appoa.com.br/uploads/arquivos/1171_utopia.pdf

FREUD, S. O mal-estar na civilização (1930 [1929]). Obras Completas. Vol.XXI. Rio de Janeiro: Imago, 1976.

. O poeta e o fantasiar (1908). In. Arte, literatura e os artistas. Tradução Ernani Chaves. Belo Horizonte: Autêntica Editora, 2015.

LACAN, J. O Seminário. Livro 20: Mais, ainda. Rio de Janeiro : Zahar, 1985.

. O Seminário. Livro 17: O avesso da psicanálise [1969-70]. Rio de Janeiro: Jorge Zahar Editor, 1992.

. O estádio do Espelho como formador da função do [eu] tal como nos é revelada na experiência psicanalítica. Escritos. Rio de Janeiro; Jorge Zahar Editor, 1998.

LYOTARD, J-F. O inumano: considerações sobre o tempo. Lisboa: Editorial Estampa, 1997.

NIETZSCHE, F. Sobre mentira e verdade em um sentido extra-moral. Obras incompletas. São Paulo: Nova Cultural, 1999.

. A gaia ciência. São Paulo: Companhia das Letras, 2001.

PAULS, A. História do pranto. São Paulo: Cosac Naify, 2008.

SCHÜLER, D. Joyce era louco? Cotia, SP: Ateliê Editorial, 2017.

SOUSA, E. L. A. Uma invenção da utopia. São Paulo: Lumme Editor, 2007. 


\title{
A Utopian Crying: Crossings Of An ALIENANT INFANTILE
}

\begin{abstract}
Through this essay, we have aimed at discussing the notion of "infantile" situated, at the same time place of its own constitution, as well as its foundational alienation as consciousness or interiority. The reading of the book "History of Crying" by Alan Pauls, has served as a device through which we have sought to analyse the anesthetic mechanisms of the experience in the contemporary, where this dimension of the infantile is "foreclosed", as well as its possible consequences to our inclination towards the utopian dream, leaving him to the mercy of adhesions or collages before these anesthetic ideals, but also, betting on the infantile that, since the freudian formulations, is presented as a factor of resistance, through the poetic potency that constitutes its utopia.
\end{abstract}

KEYWORDS: Infantile; Alienation; Contemporary; Utopia; Psychoanalysis 


\section{Un Pleurer Utopien: Croisements D'un INFANTILE ALIENANT}

\section{RÉSUMÉ}

A travers cet essai, nous essayons de discuter de la notion d'infantile située, à la fois lieu de sa constitution et de son aliénation fondamentale comme la conscience ou l'intériorité. La lecture de l'ouvrage d'Alan Pauls, Histoire de pleurer, a été un outil permettant d'analyser les mécanismes anesthésiques de l'expérience dans le monde contemporain dans lesquels cette dimension de l'enfantile est "forclos", ainsi que ses conséquences possibles pour notre inclination au rêve utopique, le laissant à la merci d'adhésions ou de collages avec ces idéaux anesthésiques, mais aussi, en pariant sur l'enfantile que se présentent les formulations freudiennes comme facteur de résistance, à travers le pouvoir poétique qui constitue son utopie.

MoTS-CLÉS: Enfance; Aliénation; Contemporain; Utopie; Psychanaly 
RECEBIDO EM 29-04-2019

APROVADO EM 25-10-2019

(C) 2019 Psicanálise \& Barroco em revista

http://www.seer.unirio.br/index.php/psicanalise-barroco/index revista@psicanaliseebarroco.pro.br

Programa de Pós-Graduação em Memória Social — UNIRIO

Memória, Subjetividade e Criação

www.memoriasocial.pro.br/proposta-area.php 